\title{
Layers of Socioeconomic Vulnerability in Malawi in the Context of the Millennium Development Goals
}

\author{
Henry V. Doctor ${ }^{1,2}$ \\ ${ }^{1}$ Department of Population \& Family Health, Mailman School of Public Health, Columbia University, 60 Haven Avenue, \\ New York, NY 10032, USA \\ ${ }^{2}$ PRRINN-MNCH Programme, 3rd Floor, Abia State House, Abuja, Nigeria \\ Correspondence should be addressed to Henry V. Doctor; hvd2105@columbia.edu
}

Received 4 December 2012; Accepted 16 January 2013

Academic Editors: B. Junquera, A. Rodriguez-Alvarez, and R. Wright

Copyright (C 2013 Henry V. Doctor. This is an open access article distributed under the Creative Commons Attribution License, which permits unrestricted use, distribution, and reproduction in any medium, provided the original work is properly cited.

Millennium Development Goal 1 focuses on the eradication of poverty and hunger by 2015. While progress towards achieving this goal is promising in many developing countries, it is estimated that 920 million people would still be living under the adjusted poverty threshold of US $\$ 1.25$ per day. This study employed data from the Malawi 2010 Demographic and Health Survey to examine the relative ranking of women $(n=23,020)$ across the wealth index scale by identifying the characteristics of women which influence their likelihood of belonging to "poor" or "rich" households. Results from the ordered probit model show that older women and those with some formal schooling were likely to fall within the higher categories of the wealth status index. Belonging to households headed by females was associated with lower categories of wealth status than those headed by males. We interpret these results in line with the current development strategies aimed at reducing poverty and hunger by 2015 and the need to identify and respond appropriately to the layers of socioeconomic vulnerability in Malawi.

\section{Introduction}

Millennium Development Goal (MDG) 1 calls for global efforts to eradicate poverty and hunger by 2015. Specifically, MDG 1 targets three areas: (a) halve the proportion of people whose income is less than US $\$ 1$ a day between 1990 and 2015, (b) achieve full and productive employment and decent work for all, including women and young people, and (c) halve the proportion of people who suffer from hunger between 1990 and 2015. Although addressing this goal has been a challenge due to the economic setbacks of the 2008-09 economic downturn, the world is generally on track to meet this goal. For example, overall poverty rates fell from $46 \%$ in 1990 to $27 \%$ in 2005 in developing regions, and progress in many developing regions is promising. Nevertheless, it is estimated that in 2015, about 920 million people would still be living under the adjusted international poverty threshold of US $\$ 1.25$ a day [1].

The need to eradicate poverty in the developing world cannot be overemphasized since, in broad terms, the level of poverty is a summary measure of individuals' ability to access resources which may improve different aspects of their lives. Along these lines, majority of countries in the world collect data periodically through household surveys and other sources in order to assess the general living conditions of people. A number of developing countries such as Malawi are undertaking efforts to reduce poverty through sustained economic growth and infrastructure development through growth development strategies. Generally, these strategies aim at transforming countries from being predominantly importing and consuming economies to predominantly manufacturing and exporting economies [2]. However, addressing issues of poverty in Malawi is an enormous task due to, among other things, challenges associated with sustainability of policy reforms, deteriorating business environment hindering private investment, low ranking on knowledge, innovation, and technology [2].

With an estimated population of 15.3 million people in 2012, Malawi is a largely rural (85\%), low income country located in south east Africa with a gross domestic product (GDP) per capita of US $\$ 370$ and a GDP growth of $4.5 \%$ per annum. Life expectancy at birth is estimated at 54 years 
whereas the poverty ratio is $67.3 \%$ [2]. In 2010, infant and under-five mortality rates were estimated at 66 and 112 deaths per 1,000 live births, respectively, whereas child mortality rate was estimated at 50 deaths per 1,000 children age $12-$ 59 months. These rates roughly represent $38 \%, 41 \%$, and $47 \%$ reduction in infant, child, and under-five mortality rates from the 2000 estimates [3]. Recent (2009) data show that Malawi has a physician density of 0.5 per 10,000 population compared with an average of 2 for Africa entirely. Accompanying the low physician density is the low density of nurses and midwives at 3 per 10,000 population compared with an average of 11 for the African region. The density of hospital beds per 10,000 population is estimated at 9 compared with 11 for the entire Africa [4].

Despite the challenges associated with macroeconomic performance and service provision to the populace, the Malawi Government with support from the international donors has engaged in a number of development strategies in order to accelerate progress towards achieving the MDGs by 2015 . In this context, this study examined the relative ranking of women interviewed in a nationally representative household survey across the wealth index scale. Specifically, the objective of the study was to identify the characteristics of women which influence their likelihood of belonging to "poor" or "rich" households. Adopting this strategy can assist policymakers in assessing the layers or profile of women and their households from which efforts to eradicate poverty can be targeted at.

The rest of the paper is organized as follows. Section 2 discusses the data and methodological issues. Section 3 presents results on the factors associated with wealth index ranking, whereas Section 4 provides a synthesis of the results and their implications on policy.

\section{Data and Methodology}

2.1. The Sample. Data for this study come from the 2010 Malawi Demographic and Health Survey (DHS). The MEASURE DHS program collected, analysed, and disseminated representative data on population, health, HIV, and nutrition through more than 200 surveys in over 75 countries throughout Africa, Asia, the Middle East, Latin America, and the Caribbean. The MEASURE DHS program is funded by the U.S. Agency for International Development including contributions from other donors as well as funds from participating countries. The program is implemented by ICF Macro, an ICF International Company. DHS typically have large sample sizes of up to 33,000 households. These surveys provide data for a wide range of monitoring and impact evaluation indicators in the areas of population, health, and nutrition.

The core questionnaire for DHS emphasizes basic indicators and flexibility. It allows for the addition of special modules in order to ensure that questionnaires can be tailored to meet host country and donor data needs. The standard DHS consists of a household questionnaire and a women's questionnaire. A nationally representative sample of women aged 15-49 years is interviewed. The household schedule collects a list of household members' information about age, sex, relationship to the head of the household, education, and parental survivorship and residence. In addition, information on household characteristics includes the source of drinking water, toilet facilities, cooking fuel, assets, and use of bed nets. Information is also collected on nutritional status and anemia with more recent DHS collecting data on HIV testing. Among other things, detailed information on reproductive health is collected including information on the height and weight of women aged 15-49 years and young children to assess nutritional status. For the same individuals, the level of haemoglobin in the blood is measured to assess the level of anemia [5].

A total of 27,307 households were sampled in the 2010 Malawi DHS of which 25,311 were occupied and a final sample of 24,825 was interviewed, a response rate of $98 \%$. From these households, 23,748 women were eligible for interviews out of which 23,020 ever and currently married women were finally interviewed representing a response rate of $96.9 \%$. This is the sample on which this study is based [3].

2.2. Variables and Definitions. The following are the core and summary variables considered in the analysis of the relationship between the profile of women and the ranking of wealth status.

2.2.1. Wealth Index. The wealth index is the dependent variable and serves as a proxy for measuring the longterm standard of living. It is constructed using information on the household's ownership of consumer goods; dwelling characteristics; type of drinking water source; toilet facilities; and other characteristics that are related to a household's socioeconomic status. To derive the index, each of these assets was assigned a weight (factor score) generated through principal component analysis, and the resulting asset scores were standardized in relation to a standard normal distribution with a mean of zero and, standard deviation of one [6]. Each household was then assigned a score for each asset, and the scores were summed for each household. Individuals were ranked according to the total score of the household in which they resided. The sample was then divided into quintiles from one (lowest or poorest) to five (highest or richest) [3].

2.2.2. Age. Measured as a continuous variable for women aged from 15 to 49 years, it is used based on the conventional wisdom on the influence of age on a number of socioeconomic outcomes such as health and other mortality outcomes. For example, older women are more likely to have completed schooling and able to engage in incomegenerating activities either through work or business activities.

2.2.3. Marital Status. The literature states that married women are more likely to have good health or socioeconomic status due to the impact of pooled income (from their husbands) on their lives [7]. Marital status is grouped into three categories: never married, married, or living together, and women who were divorced, separated, or widowed at the time of the survey. 
2.2.4. Sex of Head of Household. A number of studies [811] have used female headship of households as a proxy for access to resources, focusing on critical socioeconomic status outcomes such as poverty and income. These studies have assumed that female-headed households are poorer than male-headed households.

2.2.5. Region of Residence. Malawi is administratively divided into three regions: northern, central, and southern. These regions have distinct characteristics that may influence ranking of wealth status. For example, based on the 2008 population and housing census, the southern region was the most populous with $45 \%$ of the total population of 13 million people whereas the central and northern regions accounted for $42 \%$ and $13 \%$ of the population, respectively [12]. Southern region is also the economic and industrial hub of the country with the central region operating more of Malawi's central administration and foreign diplomatic mission activities than the other regions. The northern region has some administrative activities and a number of mining (small scale) and agricultural activities. There are also pronounced regional variations with the national adult (15-49 years) HIV/AIDS prevalence estimates in 2010 (10.6\%) being concentrated more in the southern (14.5\%) than the central (7.6\%) and northern regions (6.6\%) [3].

2.2.6. Religion. The relationship between religious affiliation and human behaviour or outcomes related to fertility, marriage, and educational attainment, among others, has been extensively studied [5, 13-15]. For example, Christianity and Islam are associated with teachings which promote healthy lives among its members such as forbidding (Islam) or liming (Christianity) alcohol intake. Nevertheless, variations do exist within select denominations of Christianity. Whereas others may ban, for example, consumption of alcohol, others may allow moderate consumption. The nonmainstream Christian groups are characteristically different from the mainstream group with the former consisting of members who yield a personal experience of the acts of the Holy Spirit of which speaking in tongues is the first outward manifestation with the Bible viewed as the foundation of the Christian faith, justifying the ultimate elimination of traditional beliefs [16].

We group religion into three categories: "mainstream Christianity" (Catholic, Presbyterian, Anglican, and Seventh Day Adventist/Baptist) "other Christian," and "Islam." The Malawi 2010 DHS data do not specify the "Other Christian" group though these are likely to include majority of Charismatic and Pentecostal churches. Those professing "no religion" or "other" unspecified group accounted for $0.84 \%$ $(n=192)$ and were excluded from the sample.

2.2.7. Schooling. Women are classified based on formal schooling: those with some formal schooling and those without. This variable serves as a proxy for the ability to improve an individual's wealth status.

2.3. Model Specification. The study uses an ordered probit model to assess the relationship between the socio-demographic factors and assessment of wealth status. The probit model is based on a formulation of a latent variable $W^{*}$ that is unobserved, that is, a woman's "true" wealth status which depends on a linear combination of explanatory variables:

$$
W^{*}=\beta^{\prime} x+\varepsilon^{\prime},
$$

where $x$ is a set of explanatory variables, $\beta$ is a set of coefficients, and $\varepsilon^{\prime}$ is an error term assumed to be uncorrelated with the set of regressors. What can, however, be observed is the following:

$$
W_{i}= \begin{cases}1 & \text { if } W^{*} \leq 1 \text { (e.g., poorest) } \\ 2 & \text { if } 1 \leq W^{*} \leq u_{1} \text { (e.g., poor) } \\ 3 & \text { if } u_{1}<W^{*} \leq u_{2} \text { (e.g., rich) } \\ J & \text { if } u_{J-1}<W^{*} .\end{cases}
$$

The $u$ 's are unknown parameters to be estimated with the $\beta$. It is important to note that $u_{0}=-\infty$ and $u_{J}=\infty$. The probability of observing $W_{i}=j$ equals the probability that the estimated linear function is within the cut-off points estimated for the outcome. In the ordered probit model $\varepsilon^{\prime}$ is assumed to be normally distributed across observations with mean of 0 and standard deviation of 1 .

In the probit regression models, the signs of the coefficients show the tendency of the variation in the probability of belonging to the highest response (or wealth group) due to an increase in the corresponding explanatory variable. A negative coefficient means that an increase in the independent variable has the effect of increasing the probability of being in a higher group of the dependent variable (see $[17,18]$ for details).

\section{Results}

3.1. Descriptive Results. Table 1 shows that women, as per the quintiles (see Section 2.2.1) of the wealth index, were equally distributed ranging from poorest to richest. The average age of women was 28.1 years. Further, $19.7 \%$ of women were never married whereas those who were married or cohabiting and those who were widowed/divorced/separated were $67.1 \%$ and $13.3 \%$, respectively. About three out of four (72.9\%) households were headed by males. Consistent with Malawi's population distribution, there were more women in the southern region (47.7\%) than the central (34.2\%) and the northern region (18.2\%). Close to half (47.0\%) of women belonged to the Mainstream Christian groups with $41.9 \%$ and $11.1 \%$ belonging to other Christian and Islamic religions, respectively. Formal school attendance was reported among $85.3 \%$ of women and in separate analyses; $78.1 \%$ of these women reported primary schooling as the highest education level.

3.2. Determinants of Wealth Status Ranking. Table 2 shows that an increase in age was associated with women falling within the higher categories of wealth status. The results also show that married/cohabiting as well as the widowed/divorced/separated women were more likely to fall 
TABLE 1: Descriptive statistics of the study population, Malawi DHS 2010 .

\begin{tabular}{|c|c|}
\hline Characteristics & $\begin{array}{c}\text { Number } \\
\text { (percentage) }\end{array}$ \\
\hline \multicolumn{2}{|l|}{ Wealth Index } \\
\hline Poorest & $4,539(19.7)$ \\
\hline Poorer & $4,506(19.6)$ \\
\hline Middle & $4,721(20.5)$ \\
\hline Richer & $4,669(20.4)$ \\
\hline Richest & $4,555(19.8)$ \\
\hline Mean age* & $28.1(9.3)$ \\
\hline \multicolumn{2}{|l|}{ Current marital status ${ }^{* *}$} \\
\hline Never married & $4,526(19.7)$ \\
\hline Married/cohabiting & $15,445(67.1)$ \\
\hline Widowed/divorced/separated & $3,049(13.3)$ \\
\hline \multicolumn{2}{|l|}{ Sex of household head } \\
\hline Male & $16,770(72.9)$ \\
\hline Female & $6,250(27.2)$ \\
\hline \multicolumn{2}{|l|}{ Region of Residence } \\
\hline Northern & $4,189(18.2)$ \\
\hline Central & $7,862(34.2)$ \\
\hline Southern & $10,969(47.7)$ \\
\hline \multicolumn{2}{|l|}{ Religion } \\
\hline Mainstream Christianity & $10,725(47.0)$ \\
\hline Other Christianity & $9,559(41.9)$ \\
\hline Islam & $2,530(11.1)$ \\
\hline \multicolumn{2}{|l|}{ Formal schooling } \\
\hline None & $3,390(14.7)$ \\
\hline Some schooling & $19,630(85.3)$ \\
\hline Number of women & $23,020(100.0)$ \\
\hline \multicolumn{2}{|c|}{$\begin{array}{l}{ }^{*} \text { Standard deviation in parentheses. Some percentages may not add up to } \\
100 \text { due to rounding of figures, and sample sizes for some subcategories may } \\
\text { not add up to the total due to sample modifications (e.g., Section } 2.2 .6 \text { on } \\
\text { religion). }{ }^{* *} \text { Cohabiting women accounted for } 8.5 \% \text { of the sample, whereas } \\
\text { the widowed, divorced, and separated accounted for } 3.7 \%, 5.1 \% \text { and } 4.4 \% \text { of } \\
\text { the sample, respectively. Differences between wealth index and each of the } \\
\text { independent variables were statistically significant }(P<0.001) \text {. }\end{array}$} \\
\hline
\end{tabular}

within the lower categories of wealth status relative to women who were never married. Households headed by women were more likely to fall within the lower categories of wealth status relative to those headed my males.

Residence in the southern and central regions was associated with lower categories of wealth status relative to residence in the northern region. With respect to Christianity, women belonging to "other Christian" denominations and Islam were more likely to belong to lower categories of wealth status than those belonging to the mainstream Christian groups. The results also show that individuals who had some formal schooling were more likely to belong to the higher categories of wealth status than women who had no formal education.
TABLE 2: Ordered probit regression analysis of wealth status ranking on selected individual characteristics, Malawi DHS 2010.

\begin{tabular}{|c|c|c|}
\hline Variable & Coefficient & $z$-statistic \\
\hline Age & 0.02 & $17.44^{*}$ \\
\hline \multicolumn{3}{|l|}{ Current marital status } \\
\hline Never married (r) & - & - \\
\hline Married/cohabiting & -0.43 & $-19.51^{*}$ \\
\hline Widowed/divorced/separated & -0.58 & $-19.32^{*}$ \\
\hline \multicolumn{3}{|l|}{ Sex of household head } \\
\hline Male (r) & - & - \\
\hline Female & -0.31 & $-16.50^{*}$ \\
\hline \multicolumn{3}{|l|}{ Region of residence } \\
\hline Northern (r) & - & - \\
\hline Central & -0.47 & $-22.68^{*}$ \\
\hline Southern & -0.23 & $-11.66^{*}$ \\
\hline \multicolumn{3}{|l|}{ Religion } \\
\hline Mainstream Christianity (r) & - & - \\
\hline Other Christianity & -0.32 & $-20.77^{*}$ \\
\hline Islam & -0.17 & $-7.23^{*}$ \\
\hline \multicolumn{3}{|l|}{ Formal schooling } \\
\hline None (r) & - & - \\
\hline Some schooling & 0.59 & $27.02^{*}$ \\
\hline $\operatorname{LR} \chi^{2}$ & $2,718.46$ & - \\
\hline Prob $>\chi^{2}$ & 0.000 & - \\
\hline Log likelihood & -35353.10 & - \\
\hline Number of observations & 22,814 & - \\
\hline
\end{tabular}

\section{Discussion}

It has been documented elsewhere [19] that individuals' access to life-enhancing resources is a critical factor in determining the well-being of their lives as well as a variety of health outcomes. For example, studies have shown that child mortality outcomes are lower among rich households than among those which are disadvantaged. As a result, efforts aimed at reducing hunger and poverty indirectly imply an improvement in health and mortality outcomes. Nevertheless, to reduce hunger and poverty, there is a need to continuously identify the various pockets of socioeconomic vulnerability in order to ensure that policies aimed at reducing hunger and poverty are targeted appropriately.

This study found that individual factors such as age and schooling have a significant and positive influence on the wealth status ranking of individuals. As expected, increased age and having some formal schooling place individuals at an advantage since they were more likely to be placed in higher categories of wealth status. However, if older women have no access to schooling, the effect of age on wealth status ranking may be attenuated. As the World Bank states, Malawi's best opportunity to improve education was at the time of this study (in 2012) since a combination of factors had set the stage for a better chance to improve education in the country [2]. The economic growth rates registered in recent years are even greater motivation to deliver better on 
education, since education plays a key role in accelerating development and economic growth activities. Another factor that can boost education is the availability of financing. By the end of 2012, Malawi's development partners had pooled close to US\$260 million to support the National Education Sector Plan (NESP). The NESP addresses priority elements in delivering quality education such as classrooms, trained teachers, teaching and learning resources, bursaries, and community participation in the delivery of education. These are serious commitments from development partners. The World Bank contributed US\$50 million with US\$90 million coming from The Fast Track Initiative (with contributions from UKaid from the Department of International Development, Germany, and UNICEF. Other partners which contributed to a pooled fund were USAID, African Development Bank, Japanese International Cooperation Agency, World Food Programme, and Canadian International Development Agency. Therefore, the government and all partners need to consolidate efforts to subscribe to the impact of education in pulling Malawi out of poverty by 2015 [2].

The finding that married/cohabiting as well as the widowed/divorced/separated women were less likely for their households to be categorized in the higher wealth status group than the never married women challenges the tenets of the role of pooled income in influencing wealth status [7]. While this may not be generalized across several countries, it is important to interpret this finding in the context of the economic performance of Malawi during the recent past. For a long time, the underlying causes of Malawi's low economic growth have been associated with, among others, weak investment and productivity growth, virtually nonexistent net fixed investment in the private sector, and growth in labor force productivity which has virtually been zero. In 2004, Malawi was investing double the dollar value of capital to yield an equivalent increase in output compared with the average in sub Saharan Africa [20]. Reliance on smallholder tobacco as the country's $50 \%$ of annual exports makes Malawi uniquely vulnerable to sector specific shocks. While an account of Malawi's economic challenges and its impact on poverty is beyond the scope of this paper, it is worth noting that as a landlocked country, Malawi faces additional challenges that need to be overcome in sending its products to international countries. Further, since the late Dr. Kamuzu Banda era (1964-1994), the Dr. Bakili Muluzi era (1994-2004), the late Dr. Bingu wa Mutharika era (2004-2012), and the current Mrs. Joyce Mtila Banda (2012-date), government policy on the role of the private sector in the country's development has generally been fragile and inhospitable [20]. Although Malawi had experienced uninterrupted concrete economic growth since 2005 for five consecutive years averaging about $7 \%$-with concomitant comprehensive economic policies and a supportive donor environment-since 2010 the policy environment began to deteriorate resulting in acute economic problems. These dynamics have compromised individuals potential to maintain higher wealth status. However, there is a need to conduct more studies to investigate the counterintuitive and interesting finding to understand why never married women were more likely to be categorized in the highest wealth status group than their counterparts since the data used in this study cannot unravel this finding.

Female-headed household were found to be disadvantaged on the wealth status scale than male-headed households. Appeals aimed at focusing on policies or interventions targeting women who head households have been the focus of debate since the early 1990s. To a large extent, targeting female headship to reduce poverty in developing countries has been considered worthwhile in theory and can also work in practice. Nevertheless, the gut of contention has been on the design and implementation of interventions that are targeted to poor female-headed families. One area which has been consistent in the literature is the fact that femaleheaded households require interventions that are directed specifically to them such as income-generating activities and child-care support, as well as affirmative policies to prevent discrimination in access to markets and resources, aggressive health and education campaigns (e.g., services for pregnant teenagers), and the establishment of effective social support networks through formal or informal organizations [21, 22]. Therefore, Malawi needs to continuously strengthen its gender-sensitive policies that benefit the average woman.

The findings again show that residence in the central and southern regions is associated with more women being categorized in the lower wealth status group than their counterparts in the northern region. Although the southern region is highly industrialized than the central and northern regions, these regional differences may be an artefact of other unmeasured outcomes in this study. For example, and as stated earlier, adult HIV/AIDS prevalence is lower in the northern region than the other regions. Differences in HIV/AIDS prevalence may put pressure on the resources of households affected by death or illness related to HIV/AIDS (e.g., [22]). The northern region is also largely Christian and historically the Livingstonia Mission of the Free Church of Scotland in northern Malawi has long been recognized as one of the pioneers of education in Malawi during the later nineteenth century. The mission established diplomatic and education networks in the northern part of Malawi and became the most effective and admired source of education for many of Malawi's early freedom fighters $[23,24]$. As a result, these results may be reflecting intergenerational effects of education compared with the southern and central regions of Malawi whose cumulated education effects may be lower than those of the north.

Related to the influence of region of residence on wealth status ranking is the influence of religion which has shown that women belonging to other Christian groups and Islam were more likely to be ranked low on the wealth status scale. While the nature of the effects of religion on wealth status ranking may be difficult to disentangle in this study due to lack of information on the religiosity of the women and the fact that religion and schooling are all independent variables; prior studies [5] showed that there are marked differences in acquisition of schooling by religious affiliation in Malawi. Using the 2000 Malawi DHS data, others [5] found that more women who identified themselves as belonging to other religions or as Muslims reported that they had never been to school compared with the average currently 
or ever-married woman. Consistently, the highest percentage of the Muslim population is in the southern region, a region which has the lowest levels of schooling. In contrast, women from Presbyterian and Catholic denominations (some of the groups making up the "mainstream Christianity" in the present study) were more likely to have some schooling than the nonreligious women. These differences, which are usually associated with the quantity of schooling, may explain the variations in the wealth status ranking and also reflected in the finding that women with some formal schooling were more likely to be ranked in the higher wealth status groups than their counterparts.

4.1. Study Limitations. The study reported here has some limitations. First, the religion variable may not permit us to assess the direct effects of religious theology, attitudes, practices, and norms related to variations in wealth status. This is critical since the religious groups considered here may have different teachings related to gender roles, female status, and education, among others [24]. Second, our study does not seek to test causality but association between wealth status ranking and the selected characteristics considered herein. Third, there are many factors that may influence or mediate the effect of the selected characteristics on wealth ranking that have not been captured. As a result, these results have to be interpreted with caution by considering these factors as layers or profiles on which socioeconomic or wealth status vulnerability can be gauged and addressed.

\section{Conclusion}

In the present study, the Malawi 2010 DHS data were used to assess the effect of selected individual characteristics of women on their wealth status ranking. The study revealed that increased age and having some formal schooling significantly influenced the likelihood of women being ranked on the higher categories of wealth status. This confirms the well-founded and currently strong recommendation by the international donor community of investing in education in Malawi by taking advantage of the Malawi National Education Sector Plan in order to accelerate efforts aimed at reducing poverty and hunger. If the overarching goal of reducing poverty and hunger is to be achieved by 2015, there is a need for policies or interventions to address the different layers of socioeconomic vulnerability that have the potential to accelerate the achievement of MDG 1. These layers include (1) the institution of marriage-which is an orientation of social and economic behaviours and a trigger for fertility outcomes, (2) the economic plight of femaleheaded households, (3) the socioeconomic and infrastructure variations at the regional level, (4) religious groups as agents of socialization and change, and (5) the interface between quantity and quality of education. Creating an enabling environment for continued policy debates on ways to respond to these layers-and other layers not considered hereshould be a priority for the Malawi Government and the development partners. We hope that this paper has rekindled the socioeconomic challenges and presented a necessary step in recognizing the angles from which poverty can be attacked as we move towards the MDG deadline of 2015 .

\section{Acknowledgments}

The author would like to thank the U.S. Agency for International Development, ICF Macro, and the National Statistical Office (Malawi) and other partners for supporting the collection and processing of the Malawi 2010 DHS data as well as making the data available for public use.

\section{References}

[1] United Nations, "Fact sheet: goal 1-eradicate extreme poverty and hunger," in Proceedings of the United Nations Summit High Level Plenary Meeting, United Nations, New York, NY, USA, September 2010.

[2] World Bank, "Malawi Country Brief," 2012, http://go.worldbank .org/PH14P64710.

[3] National Statistical Office (NSO) and ICF Macro, Malawi Demographic and Health Survey 2010, NSO and ICF Macro, Calverton, Md, USA, 2011.

[4] J. Novignon, R. Mussa, T. Msonda, and J. Nonvignon, "The use of non-prescription medicine versus self-assessed health: evidence from Malawi," International Archives of Medicine, vol. 4, no. 1, p. 38, 2011.

[5] H. V. Doctor, "Women's schooling and religious affiliation in Malawi at the end of the twentieth century," International Journal of Educational Development, vol. 25, no. 5, pp. 481-492, 2005.

[6] D. R. Gwatkin, S. Rutstein, K. Johnson, R. P. Pande, and A. Wagstaff, Socio-Economic Differences in Health, Nutrition, and Population, HNP/Poverty Thematic Group, World Bank, Washington, DC, USA, 2000.

[7] L. J. Waite and E. L. Lehrer, "The benefits from marriage and religion in the United States: a comparative analysis," Population and Development Review, vol. 29, no. 2, pp. 255-276, 2003.

[8] L. K. Staten, D. L. Dufour, J. C. Reina, and G. B. Spurr, "Household headship and nutritional status: female-headed versus male/dual-headed households," American Journal of Human Biology, vol. 10, no. 6, pp. 699-709, 1998.

[9] R. S. Katapa, "A comparison of female- and male-headed households in Tanzania and poverty implications," Journal of Biosocial Science, vol. 38, no. 3, pp. 327-339, 2006.

[10] A. McDaniel, "Historical racial differences in living arrangements of children," Journal of Family History, vol. 19, no. 1, pp. 57-77, 1994.

[11] P. R. Ulin, "African women and AIDS: negotiating behavioral change," Social Science and Medicine, vol. 34, no. 1, pp. 63-73, 1992.

[12] Malawi National Statistical Office, 2008 Population and Housing Census: Preliminary Report, National Statistical Office, Zomba, Malawi, 2008.

[13] J. Simons, "Reproductive behaviour as religious practice," in Determinants of Fertility Trends: Theories Reexamined, C. Höhn and R. Mackenson, Eds., Ordina, Liège, Belgium.

[14] R. Lesthaeghe, "A century of demographic and cultural change in Western Europe: an exploration of underlying dimensions," Population and Development Review, vol. 9, no. 3, pp. 411-435, 1983. 
[15] K. L. Brewster, E. C. Cooksey, D. K. Guilkey, and R. R. Rindfuss, "The changing impact of religion on the sexual and contraceptive behavior of adolescent women in the United States," Journal of Marriage and Family, vol. 60, no. 2, pp. 493504, 1998.

[16] M. De Witte, "Altar media's living word: televised charismatic christianity in Ghana," Journal of Religion in Africa, vol. 33, no. 2, pp. 172-202, 2003.

[17] W. H. Greene, Econometric Analysis, Pearson Education Inc, New Jersey, NJ, USA, 5th edition, 2003.

[18] A. Booth and N. Carroll, "The Health Status of Indigenous Australians," Center For Economic Policy Research Discussion Paper, University of Essex, Essex, UK, 2005.

[19] S. H. Preston and P. Taubman, Socioeconomic Differences in Adult Mortality and Health Status, National Academy Press, Washington, DC, USA, 1994.

[20] R. Record, "From policy to practice: changing government attitudes towards the private sector in Malawi," Journal of International Development, vol. 19, no. 6, pp. 805-816, 2007.

[21] M. Buvinić and G. Rao Gupta, "Female-headed households and female-maintained families: are they worth targeting to reduce poverty in developing countries?" Economic Development and Cultural Change, vol. 45, no. 2, pp. 258-280, 1997.

[22] E. Schatz, S. Madhavan, and J. Williams, "Female-headed households contending with AIDS-related hardship in rural South Africa," Health and Place, vol. 17, no. 2, pp. 598-605, 2011.

[23] F. J. Nieuwenhuis, The Development of Education Systems in Postcolonial Africa: A Study of a Selected Number of African Countries, Human Sciences Research Council, Pretoria, South Africa, 1996.

[24] B. K. Takyi and I. Addai, "Religiousaffiliation and women's educational attainment in a developing society," Sociology of Religion, vol. 63, no. 2, pp. 177-193, 2002. 


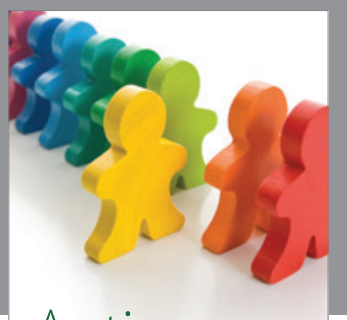

Autism

Research and Treatment
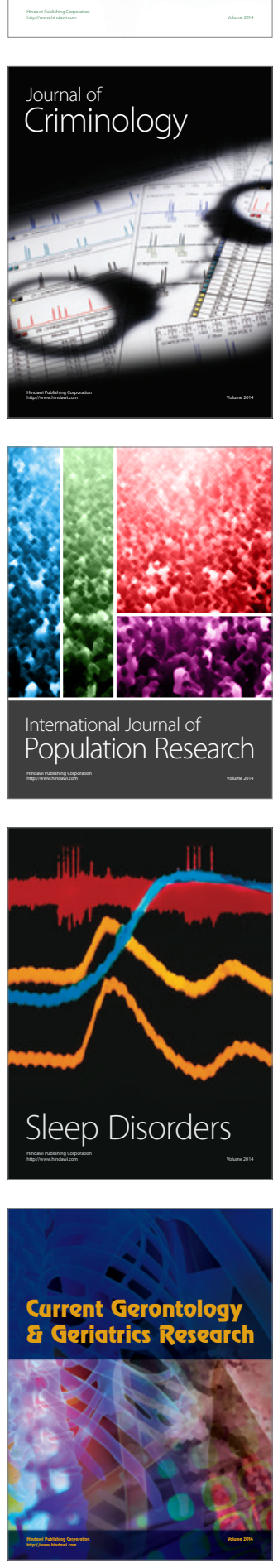
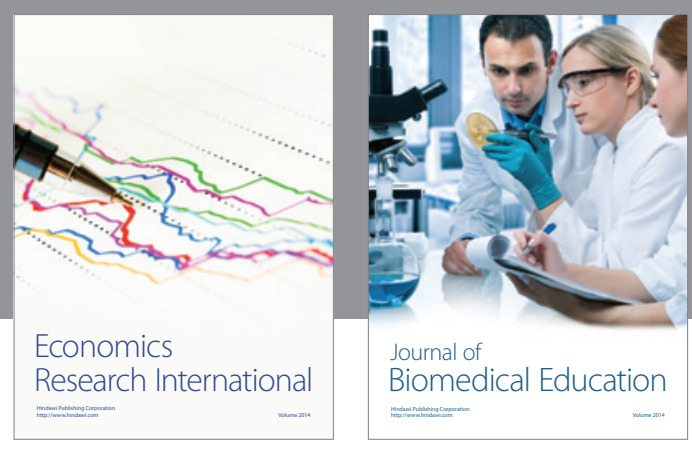

Journal of

Biomedical Education

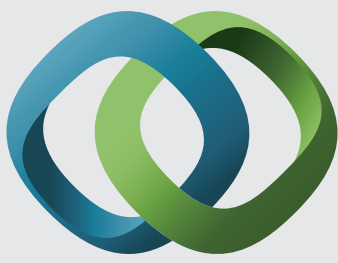

\section{Hindawi}

Submit your manuscripts at

http://www.hindawi.com
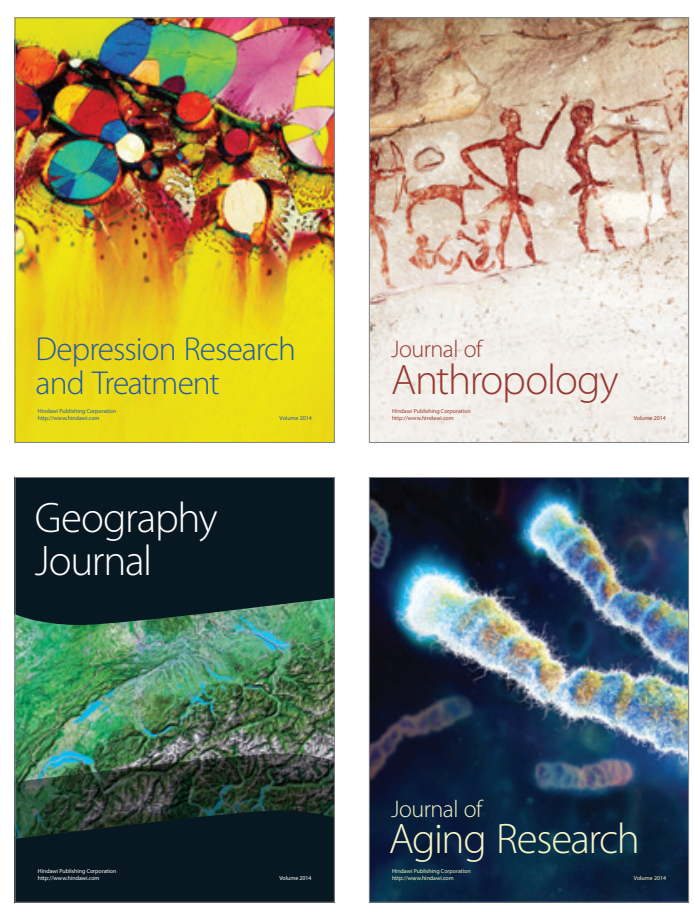

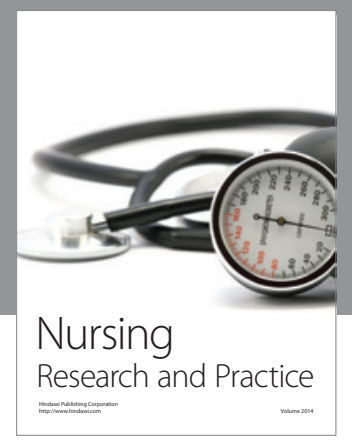

Nursing

Research and Practice

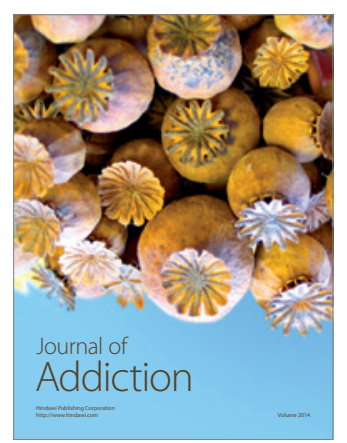

Child Development

Research

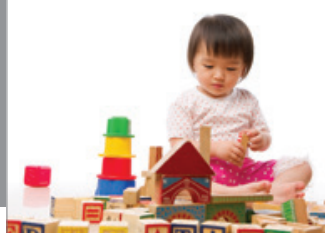

迥
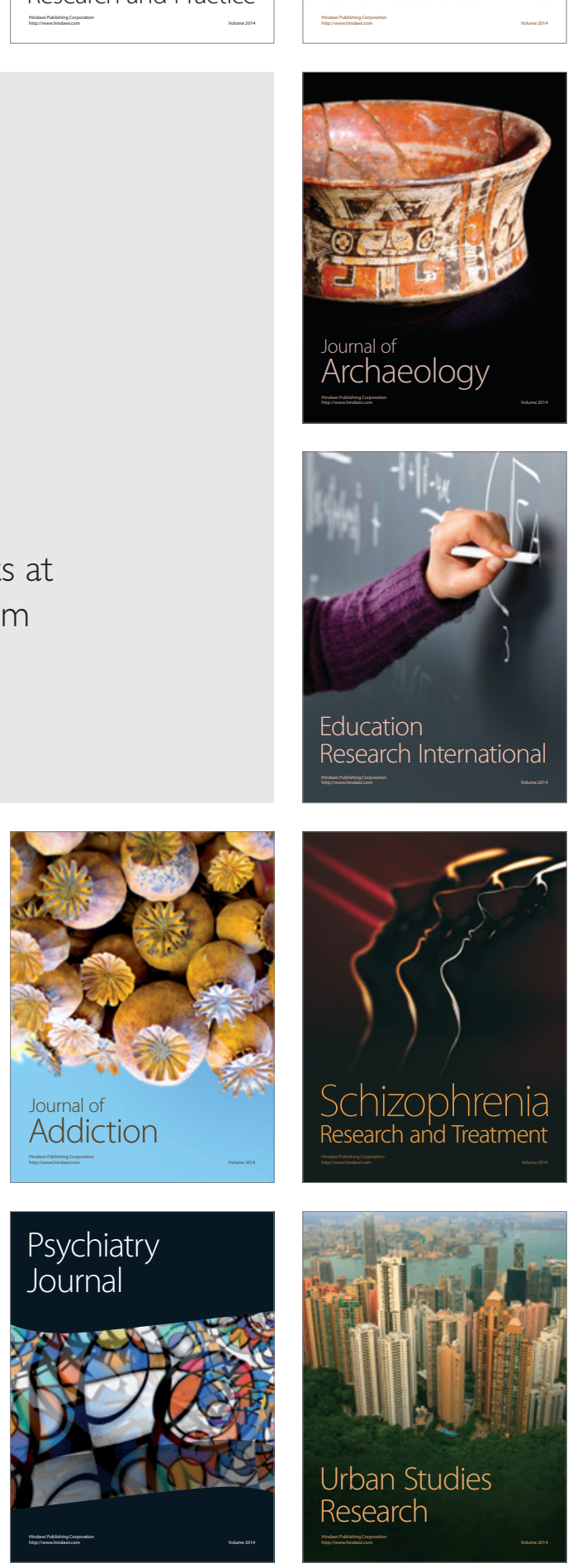